FRÜHMITTELALTERLICHE STUDIEN

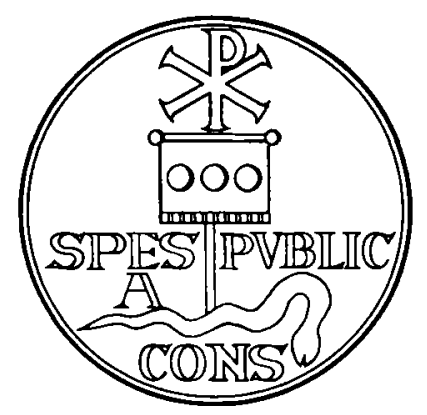





\title{
FRÜHMITTELALTERLICHE STUDIEN
}

\author{
Jahrbuch des Instituts für Frühmittelalterforschung \\ der Universität Münster
}

\begin{abstract}
in Zusammenarbeit mit
Hans Belting, Hugo Borger, Dietrich Hofmann, Karl Josef Narr, Friedrich Ohly, Karl Schmid, Rudolf Schützeichel und Joachim Wollasch

\author{
herausgegeben von
}

KARL HAUCK
\end{abstract}

10. Band

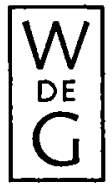

1976

WALTER DE GRUYTER · BERLIN · NEW YORK 
Dieses Jahrbuch ist im Sonderforschungsbereich 7: 'Mittelalterforschung' (Bild, Bedeutung, Sachen, Wörter und Personen)' entstanden und wurde auf seine Veranlassung unter Verwendung der ihm von der Deutschen Forschungsgemeinschaft zur Verfügung gestellten Mittel gedruckt.

Copgright 1976 by Walter de Gruyter \& Co., rormals G. J. Gosschen'sche Verlagshandlung - J. Guttentag, Verlagsbuchbandlung Georg Reimer - Karl J. Trübner - Veit \& Comp. - Printed in Germany - Alle Rechte des Nachdrucks, einschließlich des Rechtes der Herstellung von Photokopien und Mikrofilmen, vorbehalten.

Satz und Druck: Walter de Gruyter \& Co., Berlin 30

Buchbinder: Lüderitz \& Bauer, Berlin 